\title{
Combining Ability of Sweetpotato Germplasm for Yield, Dry Matter Content, and Anthocyanin Production
}

\author{
Steven M. Todd ${ }^{1}$ \\ Department of Horticultural Science, Box 7609, 214 Kilgore Hall, North Carolina State University, \\ Raleigh, NC 27695-7609 \\ Van-Den Truong \\ USDA-ARS Food Science Research Unit, 322 Schaub Hall, Box 7624, North Carolina State \\ University, Raleigh, NC 27695-7624 \\ Kenneth V. Pecota and G. Craig Yencho ${ }^{2}$ \\ Department of Horticultural Science, Box 7609, 214 Kilgore Hall, North Carolina State University, \\ Raleigh, NC 27695-7609
}

\begin{abstract}
AdDITIONAL INDEX wORDs. general combining ability, heritability, Ipomoea batatas, NCII design, specific combining ability
ABstract. Interest in the potential of sweetpotato (Ipomoea batatas) for the production of industrial products is increasing. As part of an effort to evaluate the potential of sweetpotatoes for starch and anthocyanin production in the southeastern United States, a $5 \times 5$ North Carolina mating design II (NCII mating design) was developed to estimate the relative importance of general and specific combining abilities for dry matter (DM) content, total monomeric anthocyanin (TMA) concentration, fresh yield, and total DM and anthocyanin yields. All five traits had significant general combining abilities (GCA). Yield and DM yield had significant specific combining abilities. Significant differences among parents were observed for all traits. Yield, DM content, DM yield, and TMA yield were significantly impacted by spatial gradients within the field, but TMA concentration was not. Many trait-pairs of interest had either genotypic and/or phenotypic correlations. Phenotypic and family mean correlations among yield, DM content, and DM yield; as well as among yield, TMA, and TMA yield suggested that improving one trait will not negatively impact other traits of importance.
\end{abstract}

Increasing demand for bioproducts and rising interest in the development of alternative crops to promote farm diversification have stimulated research on alternative feedstocks for production of starches, sugars, and other natural plant-derived products (Harwood et al., 1999; Henry, 2010). Sweetpotatoes with higher starch content may allow farmers to produce sweetpotatoes for industrial starch production, which can be used directly in the food and paper industries or to produce a number of biobased chemicals including biofuels and plastic precursor molecules (Ellis et al., 1998; Werpy and Petersen, 2004), thus opening new markets. Sweetpotatoes may also have potential as a source of anthocyanins for use as a natural food colorant and functional food ingredients because of their recognized antioxidant and anticancer properties (Philpott et al., 2004; Teow et al., 2007). In some regions of the world, purple-fleshed sweetpotatoes are commonly consumed in a variety of forms (e.g., boiled, baked,

Received for publication 28 Jan. 2015. Accepted for publication 14 Apr. 2015 This article is adapted from the North Carolina State University $\mathrm{PhD}$ dissertation by Steven M. Todd. We thank Roger Thompson, USDA-ARS Food Science Unit, Raleigh, NC for technical work, and the field personnel at the North Carolina Department of Agriculture and Consumer Services, Horticultural Crops Research Station, Clinton, NC, for assistance with planting, tending, and harvesting plots. Mention of trade names or commercial products in this publication is solely for the purpose of providing specific information and does not imply recommendation or endorsement by the USDA. USDA is an equal opportunity provider and employer.

${ }^{1}$ Current address: USDA-ARS Soybean and Nitrogen Fixation Unit 3127 Ligon St, Raleigh, NC 27607-5376

${ }^{2}$ Corresponding author. E-mail: craig_yencho@ncsu.edu. and mashed), while in others, notably Japan and China, purplefleshed cultivars are also used as a source of industrial anthocyanins (Suda et al., 2003).

Interest in sweetpotato anthocyanins for industrial food colorants and antioxidant additives is rising as demands for natural products and health foods increase (Shahidi, 2000). Purple-fleshed sweetpotatoes have significant untapped potential as a source of cyanidin and peonidin (Odake et al., 1992). The anthocyanins from purple-fleshed sweetpotatoes have shown significant antioxidant activity, which is associated with anticancer and other health promoting properties (Teow et al., 2007). To develop this potential market in the United States, we are developing purple-fleshed cultivars adapted to local growing conditions. Since few purple-fleshed cultivars have been introduced to the United States, purplefleshed lines have been crossed with a broad range of germplasm (orange, white, and purple clones) with offspring being selected for adaptation to the southeastern United States and high concentrations of anthocyanins. As part of this breeding effort, the inheritance of TMA concentration in the populations was studied.

Sweetpotatoes may be suitable as an industrial bioproduct feedstock because they can be grown on marginal soils with lower inputs of fertilizer and pesticides than other crops, thus reducing competition with food and feed crops and reducing the need for chemical inputs that require fossil fuels in their production (Woolfe, 1992). Increased farm diversity reduces risk over specialized farms because at times when one commodity has 
lower prices, another may have higher prices. However, a grower's decision to diversify is impacted by additional factors including management knowledge, required capital investments, and availability of suitable crops and/or livestock (Harwood et al., 1999).

Development of regionally adapted, high-starch and/or purplefleshed sweetpotato may allow development of new sweetpotatobased industries in North Carolina and the southeastern United States. In response to the rising needs for feedstocks and crop diversification, intensive breeding efforts to increase biomass and anthocyanin production from sweetpotato have begun. To date, most sweetpotato breeding efforts in the United States have focused on development of orange-fleshed, low dry-matter, tablestock cultivars. As a result, little information is available for critical bioproduct production traits such as DM, starch content, total fresh yield, and anthocyanin levels. To further understand the genetic basis of these important traits for bioproduct production, an NCII mating design (i.e., a factorial crossing block in which a set of females is crossed in all possible combinations to an independent set of males) (Comstock and Robinson, 1948) experiment was undertaken to identify combining abilities and genetic variances underlying these traits.

This paper describes an NCII breeding experiment to identify combining abilities of potential sweetpotato parents for DM and anthocyanin production. These two components may allow development of new sweetpotato processing industries in the southeastern United States. DM content is closely correlated with starch content (Hall and Smittle, 1983), and the relative ease of measuring DM content has allowed breeders to use it as an estimate of relative starch content. While many purple-fleshed cultivars have low anthocyanin concentrations and/or are unadapted to North Carolina, breeding efforts are showing that adapted cultivars with high anthocyanin concentrations can be developed.

\section{Materials and Methods}

Crossing block development. In 2003, a diallel mating design was carried out to test compatibility of sweetpotato lines to aid in selection of parents for further study. Parents were selected to represent clones with high DM content and purple flesh that could be used in a breeding program to increase the DM content, starch, and anthocyanin yield. Twenty-two parents were crossed in all possible combinations to determine compatibility. From this crossing block, five female and five male parents were found to be compatible in all needed combinations and used to develop the NCII mating block described in this paper (Table 1).

FiELD TRIALs. Twenty-five offspring of each full-sib family were evaluated in the field at the Horticultural Crops Research Station in Clinton, NC during the 2004 growing season. Each seed was planted and sprouted in the greenhouse in $6 \times 12$ cell seedling trays and the seedlings were transplanted to the field on 23 June 2004. Vine cuttings were taken to obtain five plants of each individual genotype, which were then transplanted into the field on 29 June 2004 in a modified randomized complete block experimental design (RCBD) with five plants per plot. The plants were spaced $30 \mathrm{~cm}$ in the row and rows were on $1.06-\mathrm{m}$ centers. Inorganic fertilizer (N-P-K) was applied per North Carolina sweetpotato crop production recommendations (Wilson et al., 1989). The trial was cultivated twice and irrigation was applied once as needed. For the modified RCBD, the five blocks (i.e., a field section 14-rows wide by 15.2-m long, with blocks arranged from front to back of the field) in the experiment consisted of a randomly selected subset of five offspring from each full-sib family. Therefore, the 25 siblings were planted out as five clonal plants per plot, with the first five siblings in block one, siblings 6-10 in block two, siblings 11-15 in block three, and so forth. The crop was harvested on 1 Nov. 2004, $125 \mathrm{~d}$ after planting.

Data collection. Sweetpotatoes were harvested with a one-row chain digger and weighed in the field to determine total fresh yield. Samples were collected and brought to the laboratory to determine their DM content and TMA content. A subset of three to five sweetpotatoes were selected at random from each plot and peeled to obtain samples between 125 and $250 \mathrm{~g}$, which were processed in a food processor and lyophilized to remove moisture and then weighed to determine dry weights. DM was calculated as grams freeze-dried weight/100 grams fresh weight (FW). TMA, expressed as milligrams cyanidine-3-glucoside per $100 \mathrm{~g}$ FW, was determined as

Table 1. Description of five female and five male sweetpotato parents crossed in a factorial crossing block to estimate combining abilities for yield, anthocyanins, and dry matter related traits.

\begin{tabular}{llll}
\hline & $\begin{array}{c}\text { Dry matter }(\mathrm{g} \text { dry matter/100 g } \\
\text { fresh matter })^{\mathrm{y}}\end{array}$ & \multicolumn{1}{c}{ Flesh color $^{\mathrm{x}}$} \\
\hline Female & & & Origin $^{\mathrm{w}}$ \\
'NC1650-8N' & 22 & Cream with purple & Cream with purple \\
'NCDM01-192' & 30 & Orange & United States \\
'L96-117' & 19 & Purple with cream & United States \\
'Okinawa' & 29 & Cream & Japan \\
'Xushu 18' & 26 & & Medium purple \\
Male & 30 & Medium purple & United States \\
'NC1554' & 30 & Dark purple & South America \\
'C. Morado' PI 531093 & 26 & White & Unknown \\
'NC415' & 32 & Cream & United States \\
'NCFTA94' & 20 & United States \\
'O'Henry' & & & \\
\hline
\end{tabular}

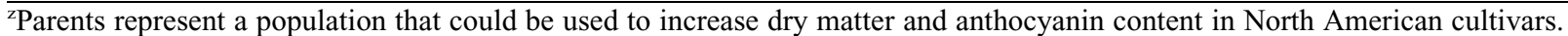

${ }^{\mathrm{y}}$ Dry matter was determined from previous measurements in North Carolina.

${ }^{x}$ Flesh color was determined from observation in previous years in North Carolina.

${ }^{\text {w}}$ Region of origin was obtained from published data or the USDA GRIN database (USDA, 2012). 
previously described (Teow et al., 2007). DM yield and TMA yield were calculated by multiplying the fresh yield by the DM content and TMA content, respectively, on an individual plot basis to estimate the production of DM and TMA per unit area.

Data ANALYSIS. Data were analyzed using JMP (version 9.0; SAS Institute, Cary, NC). Tests were carried out for GCA of the female and male parents and specific combining ability (SCA) of the crosses, for each of five traits: fresh yield, DM content, TMA content, DM yield ( = fresh yield $\times$ DM), and TMA yield (= fresh yield $\times$ TMA). The linear model used for all traits was: $\mathrm{Y}=\mu+\beta_{1} \mathrm{~F}+\beta_{2} \mathrm{M}+\beta_{3}(\mathrm{~F} \times \mathrm{M})+\beta_{4} \mathrm{~B}+\varepsilon$; where $\mathrm{Y}$ is the phenotypic trait, $\mu$ is the intercept (population mean), $\beta_{1}$ is the coefficient of regression for females (F), $\beta_{2}$ is the coefficient of regression for males $(M), \beta_{3}(F \times M)$ is female $\times$ male interaction and its coefficient, $\beta_{4} \mathrm{~B}$ is the in-field block effect (B) and its coefficient, and $\varepsilon$ is the error term. All factors were considered fixed effects. GCA was considered significant for a trait if the female and/or male parents had a statistically significant effect. SCA was considered significant if the parents demonstrated a statistically significant female $\times$ male interaction for the trait. Trait correlations were analyzed using the multivariate option in JMP (version 9.0). Phenotypic correlations were calculated on the raw data from individual plots. Family mean correlations were calculated based on the adjusted mean of each full-sib family.

\section{Results and Discussion}

The combining abilities of five traits important to sweetpotato breeding were analyzed using parents representing a population of sweetpotato breeding clones available for DM and anthocyanin improvement in North America. Sample size in this study was limited by cross incompatibilities in sweetpotato and resource availability limited the number of environments in which the population could be grown. Because of these limitations, the conclusions drawn from this research are limited; therefore, results are presented in the form of mean squares, rather than more broadly applicable heritability estimates.

Family diversity. Cultivated sweetpotato $(2 \mathrm{n}=6 \mathrm{x}=90)$ is widely recognized as a diverse species and the 25 full-sib families, of 20-25 progeny each, generated in this experiment demonstrated extensive diversity for storage root shape, color, and size. Offspring flesh colors included white, cream, orange, white with purple, purple, and purple with orange. Intensity of orange and purple flesh color varied widely even among full-sibs.
Most families contained offspring with colors and/or coloring patterns that were not present in either parent. Such transgressive segregation is likely due to the highly heterozygous, autohexaploid nature of sweetpotato. 'L96-117' $\times$ 'NC415', a cross of an orange parent by a purple, generated one of the most diverse full-sib families in the trial, with offspring bearing orange, purple, and cream flesh (Fig. 1A). 'NCDM01-192' $\times$ 'NC415', a cross between the two darkest purple parents in the population, produced offspring ranging from dark purple to cream, with diverse color patterns (Fig. 1B). 'Xushu18' $\times$ 'NC415' shows that dark purple offspring can still be obtained in a white $\times$ purple cross (Fig. 1C). A cross of two white sweetpotato cultivars (Xushu18 $\times$ NCFTA94) shows that white sweetpotato genotypes produce predominantly white offspring, traces of purple can occasionally be found in some white $\times$ white crosses (Fig. 1D).

Fresh yiELd. Male and female parents both had a significant effect on offspring yield, indicating a significant GCA, but significant female $\times$ male interaction indicated that SCA also significantly influenced offspring yield. In this experiment, a significant block effect was also observed indicating that the
A

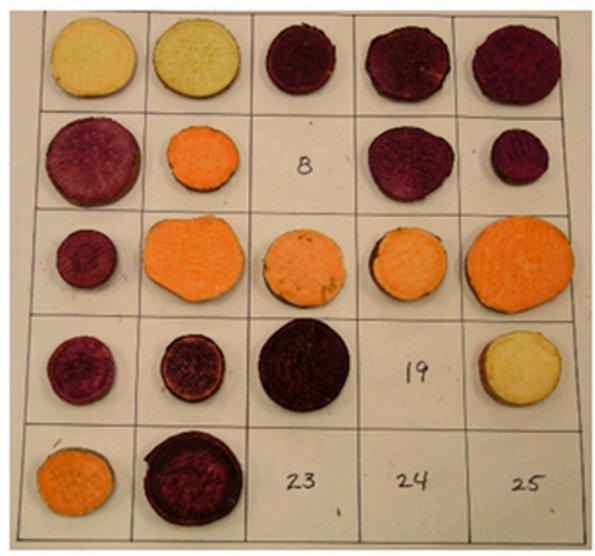

$\mathrm{C}$

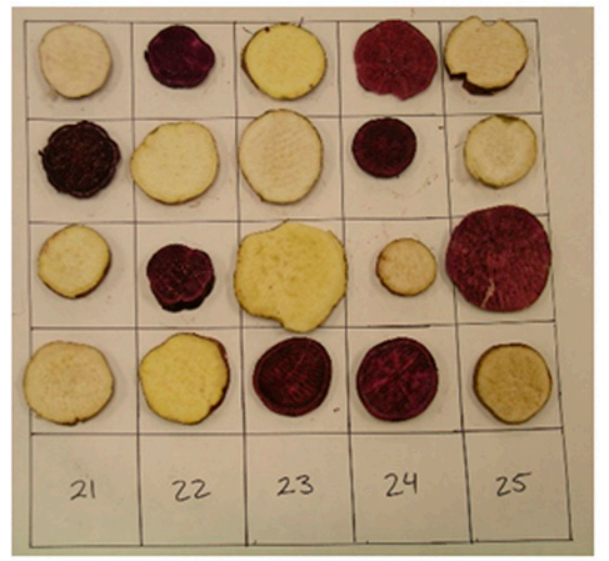

B

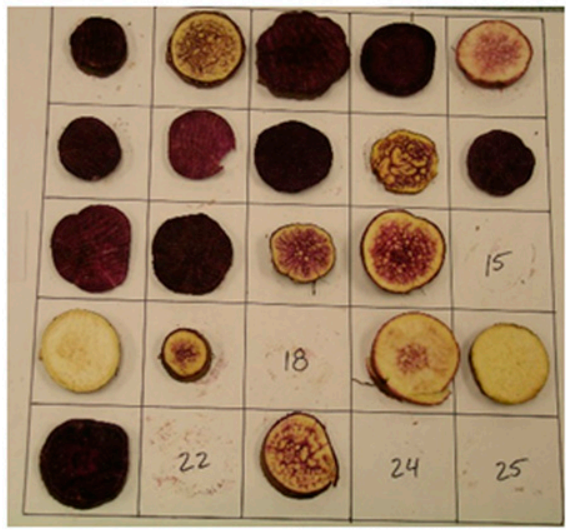

$\mathrm{D}$

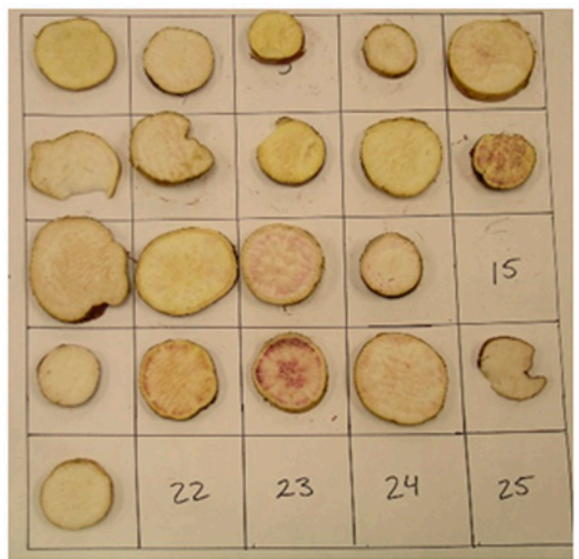

Fig. 1. Selected samples of digital images taken of each of 25 segregating full-sib sweetpotato families. Each storage root slice represents a single member of a full-sib family consisting of 20-25 siblings. (A) 'L96-117' $\times$ 'NC415', an orange parent crossed by a purple; (B) 'NCDM01-192' $\times$ 'NC415', the two darkest purple parents in the population: (C) 'Xushu18' (white parent) $\times$ 'NC415' (purple parent); (D) A cross of two white sweetpotatoes ('Xushu18' $\times$ 'NCFTA94'). 
within field variation had a large impact on fresh yield of sweetpotato. The $R^{2}$ value of the model was 0.38 , suggesting that fresh yield is somewhat difficult to predict via parental combining abilities. The relative difficulty in predicting total fresh yield agrees with past experience, as unselected (first year) full- and half-sib families normally vary widely for total fresh yield. Comparing the mean squares of each component in the model suggests the relative importance of each component in the model. In-field blocks showed the largest mean square, indicating it had the largest impact on fresh yield in this experiment. This was followed closely by females, with males and SCA having much smaller effects (Table 2).

Both male and female parents showed significant differences in the yield of their offspring, but the fresh yield range for paternal parents was generally narrower than for female parents (Table 3). The different effects of females and males on yield could be attributed to two reasons. There may be a significant maternal effect on total yield, or due to the small sample size, there may be a greater diversity among the female parents, causing them to have a larger variance component. While previous studies on maternal effects have been undertaken in sweetpotato, results have been mixed. Lin et al. (2007) demonstrated significant maternal effects on yield in one population, but not in another. In other clonally propagated crops, significant maternal effects on yield have been found in potato (Solanum tuberosum; Sanford and Hanneman, 1980).

Because all traits have significant GCAs, it is likely that all traits can be improved via polycross nurseries, which have been common in sweetpotato breeding since they were first proposed in the 1960s (Jones, 1965). However, the significant SCA for fresh yield (Table 2) suggests potentially valuable adjustments to the polycross nursery breeding approach. Because yield was significantly impacted by SCA, full-sib families were analyzed to identify those that exhibited significant SCA. Six families were found to have significant SCAs, as their yields were different from expected based on the GCAs of the two parents (Table 4). Polycross nurseries have the advantage of producing large numbers of seeds that are difficult to develop with paired crosses by hand because of the breeding behavior of sweetpotato. However, because they only allow direct control of the

Table 2. Analysis of variance of fresh yield, dry matter content, dry matter yield, total monomeric anthocyanin content, and anthocyanin yield in a five male by five female NCII sweetpotato mating experiment.

\begin{tabular}{|c|c|c|c|c|c|c|c|c|c|c|}
\hline & \multicolumn{2}{|c|}{ Fresh yield $^{\mathrm{z}}$} & \multicolumn{2}{|c|}{ DM content ${ }^{\mathrm{y}}$} & \multicolumn{2}{|c|}{ DM yield $^{x}$} & \multicolumn{2}{|c|}{ TMA content $^{\mathrm{w}}$} & \multicolumn{2}{|c|}{ TMA yield $^{v}$} \\
\hline & $\mathrm{df}$ & Mean square ${ }^{u}$ & $\mathrm{df}$ & Mean square & $\mathrm{df}$ & Mean square & $\mathrm{df}$ & Mean square & df & Mean square \\
\hline Full model $^{t}$ & 28 & $58 * * *$ & 28 & $263 * * *$ & 28 & $5.7 * * *$ & 28 & $25,629 * * *$ & 28 & $54,964,040 * * *$ \\
\hline Female & 4 & $159 * * *$ & 4 & $457 * * *$ & 4 & $18.8^{* * *}$ & 4 & $20,459 *$ & 4 & $93,194,170 * * *$ \\
\hline $\mathrm{F} \times \mathrm{M}$ & 16 & $14 * * *$ & 16 & 17 & 16 & $1.6^{* * *}$ & 16 & 6,137 & 16 & $14,731,196$ \\
\hline Block & 4 & $185 * * *$ & 4 & $635 * * *$ & 4 & $13.8 * * *$ & 4 & 2,589 & 4 & $46,154,930^{*}$ \\
\hline Error & 485 & 5 & 485 & 12 & 485 & 0.6 & 434 & 6,142 & 434 & $16,611,643$ \\
\hline
\end{tabular}

${ }^{\mathrm{z}}$ Measured in kilograms per plot.

y Dry matter content (grams dry weight/100 g FW).

${ }^{x}$ Dry matter yield (kg/plot).

"Total monomeric anthocyanin content measured as cyanidine-3-glucoside equivalents (milligrams/100 g FW).

${ }^{\mathrm{v}}$ Anthocyanin yield per plot (mg/plot).

$\mathrm{u} *, * *$, and $* * *$ indicate significance at the $0.05,0.01$, and 0.001 levels respectively.

tThe full model for analysis included female parents, male parents, female $\times$ male, and block variation. Blocks consisted of sections within a field in Clinton, $\mathrm{NC}$ in 2004.

Table 3. Adjusted mean values of sweetpotato half-sib families grown at Clinton, NC in 2004 for fresh yield, dry matter (DM) content, dry matter yield, total monomeric anthocyanin (TMA) content, and anthocyanin yield.

\begin{tabular}{|c|c|c|c|c|c|}
\hline & $\begin{array}{c}\text { Fresh yield } \\
(\mathrm{kg} / \mathrm{plot})\end{array}$ & $\begin{array}{c}\text { DM content } \\
(\mathrm{g} / 100 \mathrm{~g} \text { fresh } \mathrm{wt})\end{array}$ & $\begin{array}{l}\text { DM yield } \\
(\mathrm{kg} / \mathrm{plot})\end{array}$ & $\begin{array}{c}\text { TMA }^{\mathrm{y}} \text { content } \\
(\mathrm{mg} / 100 \mathrm{~g} \text { fresh } \mathrm{wt})\end{array}$ & $\begin{array}{c}\text { TMA yield } \\
(\mathrm{mg} / \mathrm{plot})\end{array}$ \\
\hline \multicolumn{6}{|l|}{ Females $^{z}$} \\
\hline 'NC1650-8N' & $1.5^{* * *} \mathrm{c}^{\mathrm{y}}$ & $37.1 \mathrm{~b}$ & $0.6^{* * *} \mathrm{c}$ & $40.71 \mathrm{ab}$ & $303^{* *} \mathrm{~b}$ \\
\hline 'L96-117' & $3.4 \mathrm{~b}$ & $33.3 * * * \mathrm{c}$ & $1.1 \mathrm{~b}$ & $40.50 \mathrm{ab}$ & $1,353 \mathrm{ab}$ \\
\hline 'Okinawa' & $2.3 * * * \mathrm{c}$ & $38.2 * * * a b$ & $0.9 * * * \mathrm{~b}$ & $48.09 \mathrm{ab}$ & $753 \mathrm{~b}$ \\
\hline 'Xushu18' & $4.7 * * * a$ & $36.9 \mathrm{~b}$ & $1.7^{* * *} \mathrm{a}$ & $33.69 \mathrm{~b}$ & $1,292 \mathrm{~b}$ \\
\hline 'NC1554' & $2.4 * * * b$ & $39.2 * * * \mathrm{a}$ & $1.0^{*} \mathrm{~b}$ & $57.27 \mathrm{~b}$ & $1,705 \mathrm{a}$ \\
\hline 'C. Morado' PI 531093 & $3.1 \mathrm{ab}$ & $38.2 * * * \mathrm{ab}$ & $1.2 \mathrm{ab}$ & $62.89 * \mathrm{~b}$ & $2,183^{*} \mathrm{a}$ \\
\hline 'NC415' & $3.0 \mathrm{ab}$ & $36.4 \mathrm{c}$ & $1.1 \mathrm{~b}$ & $96.24 * * * \mathrm{a}$ & $2,999 * * * \mathrm{a}$ \\
\hline 'NCFTA94' & $3.7 * * \mathrm{a}$ & $37.8^{* *} \mathrm{~b}$ & $1.4^{* * *} \mathrm{a}$ & $8.63 * * * \mathrm{c}$ & $-203 * * * \mathrm{~b}$ \\
\hline 'O’Henry' & $3.5 \mathrm{a}$ & $32.6^{* * *} \mathrm{~d}$ & $1.1 \mathrm{~b}$ & $10.20 * * * \mathrm{c}$ & $10 * * * b$ \\
\hline
\end{tabular}

${ }^{\mathrm{z} E a c h}$ half sib-sib family consisted of five full-sib families. Each full-sib family contained 20-25 members.

$\mathrm{y} *, * *$, and $* * *$ indicate family is significantly different from the population mean with a significance of $0.05,0.01$, and 0.001 respectively. Tukey's HSD was used to compare parents for each trait, those with the same letter indicator were not significantly (NS) different from each other (NS at $P=0.05$ ). 
female in a given cross, their ability to take advantage of SCA for traits of importance is reduced. While within family selection followed by asexual propagation can take advantage of SCA, the number of seeds produced by well-performing fullsib families is unknown and likely reduced in a polycross nursery as compared with paired crosses. This limitation has led to the suggestion that sweetpotato breeding programs should consider using more paired crosses, which are more efficient in terms of genetic gain (Grüneberg et al., 2009). But in breeding programs that have limited technical resources (i.e., labor for manual crossing), the limited seeds that can be obtained from paired crosses mean that the primary means of generating genetic variability for these programs will continue to be polycross nurseries. However, it may be possible to combine the attributes of paired crosses and polycrosses using a "modified polycross nursery." Typically, parents for polycross nurseries are selected based on the phenotypic qualities of the parents and then randomly ordered within a nursery. To improve traits with significant SCA such as yield, it may be advantageous to first identify crosses that produce high-yielding progeny through smaller scale paired crossing experiments. Then, to generate larger number of seedlings, parents could be selected based on the progeny testing and located in polycross nurseries such that parents with favorable SCAs were closer to each other in the nursery than may happen through standard randomization. While the effect of spacing on cross-pollination rates in a sweetpotato polycross nursery is unknown, some studies (Hittle, 1954; Tysdal and Crandal, 1948) indicate that such nonrandom spacing may increase the likelihood of combining desirable parents, although others (Wassom and Kalton, 1958) suggest that parental location in a polycross nursery has no effect on specific combination rates. This "modified polycross format" may take advantage of the strengths and help alleviate the weaknesses of polycross nurseries (i.e., large seed number, but random parentage).

DM CoNTENT. Significant SCA for DM content was not observed in this study. However, the trait was influenced by both male and female GCA and block effects. The $R^{2}$ for the model was 0.57 , indicating that parental combining ability together with in-field variation was a good indicator of offspring DM in this set of genetic materials. The mean squares of female, male, and block indicated that their impacts on DM content was about equal, although males appeared to have a slightly larger effect than females (Table 2). Both female and male parents were ranked by their ability to produce high DM offspring (Table 3 ).

DM content is often used in sweetpotato as a substitute for starch content due to the high correlation between the two traits (Hall and Smittle, 1983) and the relative ease of measuring DM content. Previous studies have found inbreeding to be an effective method of increasing DM (Komaki et al., 1998), a discovery which suggests DM is primarily controlled by additive effects, as a significant dominance effect would result in inbreeding depression. The high GCA and nonsignificant SCA for DM content in this experiment also support the hypothesis that DM content is primarily influenced by additive effects. As such, DM content could likely be effectively improved using polycross nurseries.

DM YIELD. For development of industrial sweetpotato, fresh yield and DM content should both be considered as components of DM yield. Since DM and fresh yield are negatively correlated, it was necessary to calculate combining abilities for DM yield independently. The mean square suggests that females had the largest impact on DM yield, followed by block variation, SCA, and male parents (Table 1). It is likely that females had such a large impact on DM yield primarily through their impact on fresh yield. The $R^{2}$ value for this model was 0.35 , suggesting that, with this set of materials, parental combining ability plus block effect was a moderate predictor of offspring DM yield. Both males and females were ranked by their ability to produce offspring with high DM yield (Table 3 ). The difference among DM yields for male parents was much narrower than for female parents (Table 3). Analysis of female $\times$ male interactions revealed several families with significant SCA for DM yield (Table 5).

TMA Content. The relatively low $R^{2}$ value $(0.21)$ of the anthocyanin model, suggesting low to intermediate heritability, is likely because even purple $\times$ purple crosses often produce significant numbers of white offspring (Fig. 1B). The discovery that white-fleshed by white-fleshed crosses can occasionally yield purple offspring (Fig. 1D) provides further explanation as to the low $R^{2}$ value for this trait. In this study, 'O'Henry' produced white offspring at a higher frequency than FTA94, but 'O'Henry' had several offspring with much higher TMA concentration than those of 'FTA94'. Thus, 'O'Henry' may be a better parent for producing offspring with high TMA concentration even though the frequency of purple offspring would likely be lower, the frequency of offspring with higher anthocyanin content would likely be higher. On the basis of these observations, we hypothesize that the frequency of purple

Table 4. Specific combining abilities (SCA) for sweetpotato full-sib families with statistically significant $(P<0.05)$ SCA for yield.

\begin{tabular}{lc}
\hline Specific combination & SCA estimate \\
\hline 'NC1650-8N' × 'NC415', & $-0.8^{* \mathrm{y}}$ \\
'L96-117' × 'C. Morado' & $1.2^{* *}$ \\
'L96-117' × 'NCFTA94' & $0.9^{*}$ \\
'L96-117' × 'O'Henry' & $-1.8^{* * *}$ \\
'Okinawa' × 'C. Morado' & $-0.9^{*}$ \\
'Xushu18' × 'NCFTA94' & $-1.4^{* *}$
\end{tabular}

${ }^{\mathrm{z}} \mathrm{SCA}$ estimates are the differences from the expected value based on the general combining ability (GCA) of each parent. Positive estimates indicate a specific combination that yields higher than would be expected from the combined GCA of the two parents while negative estimates indicate a lower than expected yield.

$\mathrm{y} *, * *$, and $* * *$ indicate significance at the $0.05,0.01$, and 0.001 levels respectively.

Table 5. Specific combining abilities (SCA) for sweetpotato full-sib families with statistically significant $(P<0.05)$ SCA for dry matter yield.

\begin{tabular}{lc}
\hline Specific combination & SCA estimate \\
\hline 'NC1650-8N' $\times$ 'NC415' & $-0.3^{* y}$ \\
'L96-117' × 'C. Morado' & $0.4^{* *}$ \\
'L96-117' × 'O'Henry' & $-0.6^{* * *}$ \\
'Okinawa' × 'C. morado' & $-0.3^{*}$ \\
'Xushu18' × 'NCFTA94' & $-0.4^{* *}$ \\
\hline
\end{tabular}

${ }^{\mathrm{z}}$ Positive SCA estimates indicate a specific combination with higher dry matter yield than would be expected from the combined general combining abilities of the two parents while negative SCA estimates indicate a lower than expected dry matter yield.

$y *, * *$, and $* * *$ indicate significance at the $0.05,0.01$, and 0.001 levels respectively. 
offspring a parent produces is not necessarily related to the TMA concentration of the purple offspring produced.

Continued breeding experience has shown these two situations (i.e., presence of purple offspring in families from white parents and presence of white offspring in families from purple parents has been observed) are the general rule rather than the exception over past years of breeding (data not shown). Biosynthesis of anthocyanins is determined by the presence of multiple necessary steps in the biochemical pathway (Holton and Cornish, 1995). Because of the highly heterozygous, autohexaploid breeding nature of sweetpotato (Cervantes et al., 2008), clones may have a complete anthocyanin pathway even if they have multiple copies of null alleles for a particular step in the pathway. Independent assortment and reduction of ploidy during meiosis can result in gametes that do not contain active alleles for particular steps in the pathway. When these gametes are combined during fertilization, two purple-fleshed parents can produce offspring with no anthocyanins. On the other hand, genetic recombination can produce offspring with a complete anthocyanin pathway even in cases in which neither or just one parent has a complete anthocyanin pathway (Fig. 1D) (Ishiguro et al., 2001; Mano et al., 2007).

Both males and females had significant effects on anthocyanin concentration, but neither SCA nor block variation had a significant impact on anthocyanin concentration (Table 2 ). In this population, males had a much larger impact on TMA than females. This was likely due to the small population size. In particular, ' $\mathrm{NC415}$ ' is known to have very high TMA and its use as $20 \%$ of the males may have resulted in an outsized effect. While other clones in the experiment range from white to purple, no parental clone in this population had TMA levels as high as 'NC415'.

Both males and females were ranked by the anthocyanin contents of their offspring (Table 3 ). One significant discovery from this experiment that will impact purple sweetpotato breeding efforts is that crossing two purple sweetpotatoes generally results in offspring with significantly higher TMA than crossing a white by a purple sweet potato. In recent years, we have significantly expanded the North American purple sweetpotato breeding pool beyond that described in this experiment. To improve adaptation, less adapted purple-fleshed lines will be crossed with highly adapted white and orange-fleshed cultivars. During the first generation of these crossing efforts, lower average TMA concentrations in purple offspring from purple $\times$ nonpurple crosses than purple $\times$ purple crosses may be expected. This suggests that recurrent selection will be required to develop adapted cultivars with high TMA, as even the purple offspring from purple by white crosses will likely have lower TMA than would be obtained from purple by purple crosses.

TMA YIELD. Similar to DM yield, fresh yield and TMA content should both be considered as component traits for TMA yield in industrial sweetpotatoes. Females, males, and blocks had significant effects on TMA yield. Mean square analyses indicated that TMA yield was primarily influenced by GCA (Table 2). Both male and female parents were ranked by their ability to produce offspring with high TMA yield (Table 3 ).

For this population, TMA yield is more heavily influenced by TMA content than fresh yield. This trend is likely affected by the diverse nature of the population, which contained several white and purple parents. Since nonpurple by nonpurple crosses produced several families with almost no TMA, no amount of fresh yield in these families would overcome the complete lack of TMA in their offspring. Similar to TMA content, males had a much larger effect than females for TMA yield; while females had a much larger effect on total fresh yield, this was not the case in TMA yield. The $R^{2}$ value for TMA yield (0.18) suggests low heritability in this set of materials and more closely resembles that for TMA content than for fresh yield. Trait correlations also showed that TMA yield was much more closely correlated with TMA content than with fresh yield. While this relationship is likely to hold for crossing blocks similar to this one, its potential impact on purple sweetpotato breeding efforts is currently unknown. The development of purple cultivars by crossing only white sweetpotatoes will not be attempted, since these families are unlikely to be productive in a concentrated effort to develop high TMA yielding cultivars.

The significant spatial effect on several traits (yield, DM, DM yield, and TMA yield) was likely due to soil variation at the site. The sand-clay ratio of the soil is highly variable at the site. While every effort was made to avoid this variation within the test, it was not always possible to avoid it completely. Soil testing done on this same site in 2010 indicated a highly variable cation exchange capacity at the location the test had been grown, which may also help explain the highly significant block effect for several traits.

Trait Correlations. Phenotypic and family mean correlations among traits described in this article revealed several correlations relevant to sweetpotato breeding (Table 6). Both

Table 6. Phenotypic (top) and family mean (bottom) trait Pearson correlation coefficients for five sweetpotato traits important for industrial sweetpotato production.

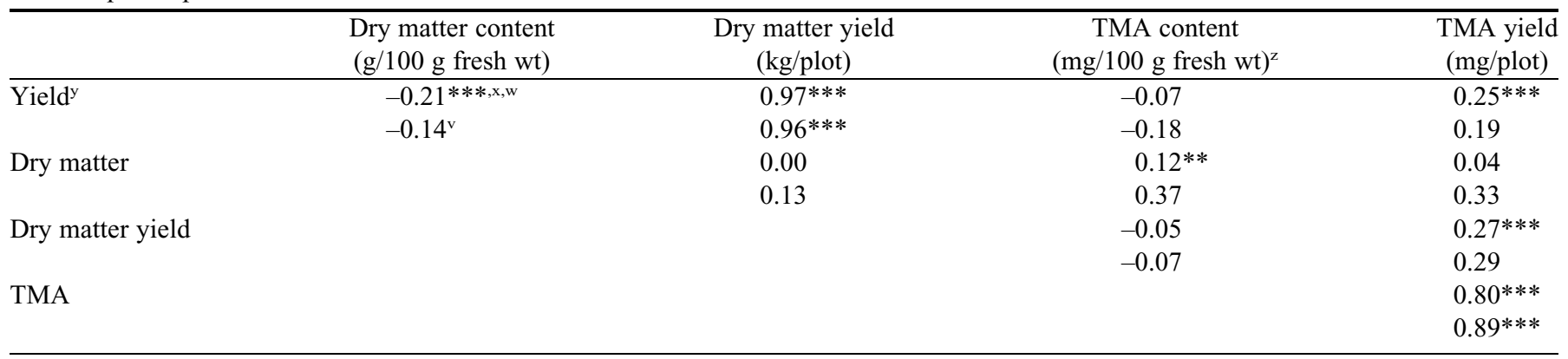

${ }^{\mathrm{z} T M A}=$ total monomeric anthocyanins measured as cyanidine-3-glucoside equivalents.

${ }^{\mathrm{y}}$ Measured in kilograms per plot.

$\mathrm{x} *, * *$, and $* * *$ indicate significance at the $0.05,0.01$, and 0.001 levels, respectively.

wPhenotypic correlations were calculated based on individual plot data.

${ }^{v}$ Family mean correlations were calculated based on the least square mean values of full-sib families. 
phenotypic and family mean correlations provide information relevant to improvement of key traits of interest: DM yield and TMA yield.

The correlations showed that DM yield is much more significantly impacted by total yield than by DM content. Phenotypic and family mean correlations among yield, DM, and DM yield indicate that improving fresh yield would likely have a positive impact on DM yield. Strong positive correlations were found between yield and DM yield (Table 6). Yield had a negative phenotypic correlation with storage root DM content $(-0.21)$, but there were no statistically significant correlations between DM content and DM yield. This suggests that breeding efforts may be better spent improving fresh yield in relatively high DM lines than attempting to increase their DM further.

The results also indicate that the TMA yield of sweetpotatoes is more closely correlated with the TMA content than with fresh yield in this population (Table 6). However, since this population contains several high-yielding parents with no TMA content, this correlation may change in another population or crossing block. TMA concentration and TMA yield possessed significant family mean correlations with DM, but their phenotypic correlations with DM were much weaker. TMA and TMA yield both had weak family mean correlations with yield, and a weak phenotypic correlation (0.12) was found between TMA and DM content. TMA yield had a strong phenotypic correlation with TMA (0.80) and a positive correlation with yield $(0.25)$.

\section{Conclusion}

A factorial mating experiment was carried out to better understand the best crossing approach to modify sweetpotatoes to meet the needs of emerging processing markets. This study included traits that had not been analyzed before in U.S. sweetpotato populations related to anthocyanin and DM production. It was demonstrated that offspring in sweetpotato can frequently show color patterns that are not present in either parent (Fig. 1), likely due to the highly heterozygous, hexaploid nature of sweetpotato. The relative importance of general and specific combining abilities were estimated for yield, DM and anthocyanin contents, and DM and anthocyanin yields. Results suggest that DM content, anthocyanin content, and anthocyanin yield are primarily influenced by GCA while fresh yield and DM yield are influenced by both GCA and SCA. The relative importance of GCA and SCA for each trait investigated leads us to suggest that sweetpotato breeders update their crossing methods from the traditional polycross approach to breeding sweetpotato (Jones, 1965). The uncontrolled crossing patterns of the polycross nursery are likely sufficient for traits with low SCA. However, for important traits like yield and DM yield with high SCA, we suggest a modified polycross nursery approach by identifying parents that produce high performing offspring before incorporating them into the polycross nursery and locating them near each other in the nursery so that they are more likely to cross with each other. Such an approach may allow breeders to take advantage of the benefits of sweetpotato polycross nurseries while also increasing the likelihood of desirable specific combinations for traits with a significant SCA.

\section{Literature Cited}

Cervantes-Flores, J., G.C. Yencho, A. Kriegner, K. Pecota, M. Faulk, R. Mwanga, and B. Sosinksi. 2008. Development of a sweetpotato genetic linkage map and identification of homologous linkage groups in sweetpotato using multiple dose AFLP markers. Mol. Breed. 21:511-532.

Comstock, R.E. and H.F. Robinson. 1948. The components of genetic variance in populations of biparental progenies and their use in estimating the average degree of dominance. Biometrics 4:254-266.

Ellis, R.P., M.P. Cochrane, M.F.B. Dale, C.M. Duffus, A. Lynn, I.M. Morrison, R.D.M. Prentice, J.S. Swanston, and S.A. Tiller. 1998. Starch production and industrial use. J. Sci. Food Agr. 77:289-311.

Grüneberg, W., R. Mwanga, M. Andrade, and H. Dapaah. 2009. Unleashing the potential of sweetpotato in sub-Saharan Africa: Current challenges and way forward. Intl. Potato Ctr., Lima, Peru. 18 Feb. 2015. <http://cipotato.org/publications/pdf/004718.pdf >.

Hall, M.R. and D.A. Smittle. 1983. Industrial-type sweetpotatoes: A renewable energy source for Georgia. Res. Rpt. Univ. Georgia College Agr. Expt. Sta. Rpt. 429.

Harwood, J., R. Heifner, K. Coble, J. Perry, and A. Somwaru. 1999. Managing risk in farming: Concepts, research, and analysis. Agr. Economics Res. Rpt. 774. U.S. Dept. Agr., Economic Res. Serv., Washington DC.

Henry, R. 2010. Plant resources for food, fuel, and conservation. Earthscan, London, UK.

Hittle, C.N. 1954. A study of the polycross progeny testing technique as used in the breeding of smooth bromegrass. Agron. J. 46:521-523.

Holton, T.A. and E.C. Cornish. 1995. Genetics and biochemistry of anthocyanin biosynthesis. Plant Cell 7:1071-1083.

Ishiguro, K., T. Kumagai, Y. Kai, Y. Nakazawa, and O. Yamakawa. 2002. Genetic resources and breeding of sweetpotato in Japan, p. 5761. In: R. Rao and D. Campilan (eds.). Proc. 3rd Intl. Wkshp. Asian Network Sweetpotato Genetic Resources (ANSWER), Denpasar, Bali, Indonesia. 2-4 Oct. 2001. Intl. Plant Genet. Resources Inst. Regional Office for Asia, the Pacific and Oceania (IPGRI-APO), Serdang, Malaysia.

Jones, A. 1965. A proposed breeding procedure for sweetpotato. Crop Sci. 5:191-192.

Komaki, K., K. Katayama, and S. Tamiya. 1998. Advancement of sweet potato for high starch content in Japan. Trop. Agr. 75:220-223.

Lin, K.H., Y.C. Lai, K.Y. Chang, Y.F. Chen, S.Y. Huang, and H.F. Lo. 2007. Improving breeding efficiency for quality and yield of sweet potato. Bot. Stud. 48:283-292.

Mano, H., F. Ogasawara, K. Sato, H. Higo, and Y. Minobe. 2007. Isolation of a regulatory gene of anthocyanin biosynthesis in tuberous roots of purple-fleshed sweet potato. Plant Physiol. 143:1252-1268.

Odake, K., N. Terahara, N. Saito, K. Toki, and T. Honda. 1992. Chemical structures of two anthocyanins from purple sweetpotato, Ipomoea batatas. Phytochemistry 31:2127-2130.

Philpott, M., K.S. Gould, C. Lim, and L.R. Ferguson. 2004. In situ and in vitro antioxidant activity of sweetpotato anthocyanins. J. Agr. Food Chem. 52:1511-1513.

Sanford, J.C. and R.E. Hanneman, Jr. 1980. Large yield differences between reciprocal families of Solanum tuberosum. Euphytica 31:1-12.

Shahidi, F. 2000. Antioxidants in food and food antioxidants. Mol. Nutr. Food Res. 44:158-163.

Suda, I., T. Oki, M. Masuda, M. Kobayahsi, Y. Nishiba, and S. Furuta. 2003. Physiologial functionality of purple-fleshed sweet potatoes containing anthocyanins and their utilization in foods. Jpn. Agr. Res. Qrtly. 37:167-173.

Teow, C.C., V.D. Truong, R.F. McFeeters, R.L. Thompson, K.V. Pecota, and G.C. Yencho. 2007. Antioxidant activities, phenolic and $\beta$-carotene contents of sweetpotato genotypes with varying flesh colors. Food Chem. 103:829-838.

Tysdal, H.M. and B.H. Crandall. 1948. The polycross progeny performance as an index of the combining ability of alfalfa clones. J. Amer. Soc. Agron. 40:293-306. 
U.S. Department of Agriculture. 2012. Germplasm Resources Information Network. 11 Mar. 2015. <http://www.ars-grin.gov/npgs/ acc/acc_queries.html>.

Wassom, C.E. and R.R. Kalton. 1958. Evaluation of combining ability in Dactylis glomerata L. IV. Randomness of pollination in topcross and polycross nurseries. Agron. J. 50:640-643.

Werpy, T. and G. Petersen. 2004. Top value added chemicals from biomass: Volume 1- Results of screening for potential candidates from sugars and synthesis gas. Tech. Rpt., Natl. Renewable Energy Lab., Golden, CO.

Wilson, G.L., C.W. Averre, J.V. Baird, E.O. Beasley, A.R. Bonanno, E.A. Estes, and K.A. Sorensen. 1989. Growing and marketing quality sweetpotatoes. North Carolina Agr. Ext. Serv. Publ. No. AG-09.

Woolfe, J.A. 1992. Sweetpotato: An untapped food resource. Cambridge Univ. Press, Cambridge, UK. 